\title{
HUBUNGAN MOTIVASI DAN DUKUNGAN PETUGAS KESEHATAN DENGAN KEPATUHAN PASIEN GAGAL GINJAL KRONIK YANG MENJALANI HEMODIALISIS DI RSUP. DR. M.DJAMIL PADANG TAHUN 2016
}

\author{
${ }^{1}$ Zuriati \\ Prodi Keperawatan STIKes Alifah, Jln Khatib Sulaiman No 52 Padang 25000 \\ Email: yathie_zuriati13@yahoo.com
}

\begin{abstract}
ABSTRAK
Penderita Gagal Ginjal kronis (GGK) terus meningkat setiap tahunnya, prevelensi GGK di Amerika Serikat lebih dari $10 \%$ atau lebih dari 20 juta orang. Indonesia mengalami peningkatan GGK sebesar $8 \%$ tiap tahun. Hemodialisa merupakan terapi pengganti utama pada pasien GGK yang membutuhkan terapi jangka panjang atau terapi permanen. Dukungan petugas kesehatan sangat penting bagi pasien yang menjalani terapi hemodialisa rutin dan merupakan salah satu faktor yang mempengaruhi kepatuhan pasien GGK untuk menjalani hemodialisa. Penelitian ini bertujuan untuk mengetahui hubungan antara motivasi dan dukungan petugas kesehatan dengan kepatuhan pasien GGK menjalani hemodialisis di RSUP Dr. M. Djamil Padang Tahun 2016.Jenis penelitian ini adalah deskriptif korelasi dengan pendekatan cross sectional study. Populasi pada penelitian ini adalah pasien yang dating menjalani terapi hemodialisa dengan Teknik pengambilan sampel adalah purposive sampling sebanyak 65 orang. Data diolah dengan menggunakan analisis univariat dan bivariat. Hasil penelitian menunjukkan 53,8\% pasien GGK yang menjalani hemodialisa memiliki motivasi yang rendah, 60,0\% memiliki dukungan petugas yang tinggi dan 64,6\% tidak patuh menjalani hemodialisa. Terdapat hubungan yang bermakna antara motivasi dengan kepatuhan pasien GGK untuk menjalani hemodialisa dengan nilai p 0,000,dan ada hubungan yang bermakna antara dukungan petugas kesehatan dengan kepatuhan pasien GGK untuk menjalani hemodialisis dengan nilai p 0,000. Berdasarkan hasil penelitian ini, diharapkan petugas kesehatan lebih mengajarkan kepada pasien untuk lebih meningkatkan lagi motivasinya dalam melakukan hemodialisa.
\end{abstract}

\section{Kata Kunci : Motivasi, Dukungan Petugas, Gagal Ginjal Kronik}

\section{ABSTRACT}

Patients with Chronic Renal Failure (GGK) continue to increase every year, the prevalence of CPR in the United States more than 10\% or more than 20 million people. Indonesia experienced an increase in CPR by $8 \%$ per year. Hemodialysis is a major replacement therapy in patients with CRF who require long-term therapy or permanent therapy. Support of health workers is very important for patients who undergo routine hemodialysis therapy and is one of the factors that influence the compliance of CPR patients to undergo hemodialysis. This study aims to determine the relationship between motivation and support of health personnel with compliance of patients with GGK undergoing hemodialysis in Dr. M. Djamil Padang Year 2016. This type of research is a descriptive correlation with cross-sectional study approach. The population in this study is the patients who come undergoing hemodialysis therapy with sampling technique is purposive sampling as much as 65 people. The data were processed by using univariate and bivariate analysis. The results showed that $53.8 \%$ of GGK patients undergoing hemodialysis had low motivation, $60.0 \%$ had high officer support and $64.6 \%$ did not adhere to hemodialysis. There was a significant association between motivation and adherence of CKG patients to hemodialysis with a p-value of 0,000 , and there was a significant relationship between the support of the healthcare provider and the compliance of the CRF patients to undergo hemodialysis with a p-value of 0.000. Based on the results of this study, it is expected that health workers teach more patients to further increase their motivation in doing hemodialysis.

Keywords: Motivation, Support Officer, Chronic Kidney Failure 


\section{PENDAHULUAN}

Ginjal merupakan organ vital bagi kelangsungan hidup manusia. Ginjal berfungsi mengatur keseimbangan cairan dalam tubuh, elektrolit dan asam basa dengan cara filtrasi darah, reabsorpsi selektif air, elektrolit dan non elektrolit serta mengeksresikan kelebihannya sebagai urine (Price \& Wilson, 2006 dalam Dani 2015). Pada saat ginjal tidak mampu untuk menjalankan fungsinya maka dapat menimbulkan gangguan ginjal dan bisa menyebabkan kematian. Salah satu gangguan ginjal adalah gagal ginjal kronis (GGK)

GGK merupakan suatu keadaan dimana terjadi penurunan fungsi ginjal yang progresif dan ireversibel sehingga tubuh gagal untuk mempertahankan metabolisme, keseimbangan cairan dan elektrolit, dan menyebabkan uremia (Smeltzer. C, Suzanne, 2002). Penderita GGK terus meningkat setiap tahunnya, berdasarkan Center for Disease Control and prevention prevalensi GGK di Amerika Serikat pada tahun 2012 lebih dari 10\% atau lebih dari 20 juta orang. Indonesia termasuk negara dengan tingkat penderita GGK yang cukup tinggi yaitu diperkirakan mengalami peningkatan sebesar $8 \%$ tiap tahun. Selain itu, penyakit GGK juga menempati urutan ke 10 dalam penyakit tidak menular (Kemenkes RI, 2013).

Hemodialisa merupakan terapi pengganti utama pada pasien GGK yang membutuhkan terapi jangka panjang atau terapi permanen (Smeltzer \& Bare, 2002). Hemodialisa di Indonesia sudah dimulai sejak tahun 1970 dan sampai sekarang telah dapat dilaksanakan di rumah sakit rujukan (Sunarni, 2009). Saat ini hemodialisa merupakan terapi pengganti ginjal yang paling banyak dilakukan dan jumlahnya dari tahun ke tahun terus meningkat. Tujuan utama hemodialisa adalah menghilangkan gejala yaitu mengendalikan uremia, kelebihan cairan, dan ketidakseimbangan elektrolit yang terjadi pada pasien GGK (Kallenbach, et al., 2005 dalam Dani 2015).

Jumlah pasien GGK yang dapat bertahan hidup terus meningkat melalui terapi hemodialisa. Tercatat setelah satu tahun melakukan hemodialisa angka harapan hidup meningkat menjadi $79 \%$
(Black \& Hawks, 2005 dalam Dani 2015). Pasien GGK sebagian dirawat di rumah sakit dan ada juga yang menjalani rawat jalan. Pasien GGK membutuhkan 12-15 jam setiap minggunya untuk melakukan hemodialisa. Pasien penyakit GGK harus terus menjalani hemodialisa seumur hidup (Lubis, 2006).

Kepatuhan dalam hemodialisa ini sangat diperlukan untuk mempertahankan kehidupan. Apabila pasien tidak patuh dalam menjalani hemodialisa akan berdampak sangat buruk karena akan berpengaruh terhadap terjadinya komplikasi akut dan kronis. Kepatuhan terapi hemodialisa juga berdampak pada berbagai aspek perawatan pasien, termasuk konsistensi kunjungan, serta pembatasan makanan dan cairan (Syamsiah, 2011). Apabila pasien tidak membatasi jumlah asupan cairan maka cairan akan menumpuk didalam tubuh dan akan menimbulkan edema disekitar tubuh seperti tangan, kaki, dan muka. Banyak penumpukan cairan terjadi di rongga perut yang membuat perut ascites, kondisi ini akan membuat tekanan darah meningkat dan memperberat kerja jantung. Penumpukan cairan juga masuk ke paru-paru sehingga pasien mengalami sesak nafas. Karena itulah perlunya pasien mengontrol dan membatasi jumlah asupan cairan yang masuk dalam tubuh. (Brunner \& Suddart, 2002)

Kepatuhan dapat dipengaruhi oleh berbagai faktor, diantaranya keyakinan, sikap dan motivasi pasien, pengetahuan, persepsi, harapan pasien, dukungan sosial keluarga, dan dukungan petugas kesehatan (Niven, 2012 dan Kamerrer, 2007). Motivasi dan harapan merupakan salah satu faktor yang dapat meningkatkan kepatuhan pasien. Motivasi merupakan sesuatu yang mendorong atau pendorong seseorang bertingkah untuk mencapai tujuan tertentu (Saam \& Wahyuni, 2012), Motivasi dan harapan sangat diperlukan untuk membantu seseorang meningkatkan kepatuhan dalam menjalani terapi hemodialisa.

Pasien yang melakukan terapi hemodialisa memerlukan dukungan dari petugas kesehatan. Dukungan petugas kesehatan sangat penting bagi pasien yang menjalani terapi hemodialisa rutin dan merupakan salah satu faktor yang mempengaruhi kepatuhan pasien GGK untuk menjalani 
hemodialisa. Dukungan mereka berguna saat pasien mengahadapi keadaan bahwa perilaku sehat merupakan hal yang sangat penting. Penelitian yang dilakukan oleh Dani tentang hubungan motivasi, harapan, dan dukungan petugas kesehatan terhadap kepatuhan pasien gagal ginjal kronik untuk menjalani hemodialisis yang menunjukkan bahwa ada hubungan yang signifikan antara motivasi terhadap kepatuhan pasien GGK untuk menjalani hemodialisa. Hal ini berarti diperlukan dukungan dari petugas kesehatan sehingga penderita dapat meningkatkan kepatuhan pasien dalam pengobatan.

Reaksi yang sering muncul pada pasien yang tidak patuh dalam menjalani hemodialisa adalah overload (kelebihan cairan) yang ditandai dengan adanya sesak nafas pada pasien, hiperuremia atau kelebihan uremia sehingga badan menjadi lelah dan nafsu makan berkurang. Penderita GGK pun sering kehilangan banyak albumin disebabkan karena saat menjalani terapi dialysis albumin terbuang, serta kurangnya produktivitas ginjal dalam memproduksi albumin dibandingkan produksi albumin didalam hati. Hal ini akan kelihatan terjadinya penumpukan cairan di perut, karena ginjal tidak mampu menyaring cairan yang masuk kedalam tubuh.

Berdasarkan uraian diatas peneliti tertarik untuk melakukan penelitian guna mengetahui "Hubungan motivasi dan dukungan petugas kesehatan terhadap kepatuhan pasien GGK menjalani hemodialisa di RSUP Dr. M. Djamil Padang tahun Rawat Inap 2016.

\section{METODA PENELITIAN}

Jenis penelitian yang digunakan adalah deskriptif korelasi yang digunakan untuk melihat hubungan antara 2 variabel yang bertujuan untuk mengetahui "Hubungan Motivasi dan Dukungan Petugas Kesehatan Terhadap Kepatuhan Pasien GGK Menjalani Hemodialisa di RSUP Dr. M. Djamil Padang Tahun 2016" melalui pendekatan Cross Sectional.. Populasi dalam penelitian ini adalah semua pasien yang datang untuk melakukan terapi hemodialisa dengan sampel 65 orang menggunakan teknik accidental sampling

\section{HASIL DAN PEMBAHASAN}

Tabel 1

Distribusi Frekuensi Motivasi Pasien GGK yang Menjalani Hemodialisa di Unit Hemodialisa RSUP Dr. M. Djamil Padang Tahun 2016

\begin{tabular}{lcc} 
Motivasi & $\begin{array}{c}\text { Frekuensi } \\
\text { (f) }\end{array}$ & $\begin{array}{c}\text { Persentase } \\
(\mathbf{\%})\end{array}$ \\
\hline Tinggi & 30 & 46,2 \\
Rendah & 35 & 53,8 \\
\hline Total & $\mathbf{6 5}$ & $\mathbf{1 0 0}$
\end{tabular}

Berdasarkan tabel 1 dapat dilihat bahwa dari 65 orang responden didapatkan lebih dari separoh 35 $(53,8 \%)$ responden memiliki motivasi yang rendah dalam menjalani hemodialisa di Unit Hemodialisa

\section{Tabel 2}

Distribusi Frekuensi Dukungan Petugas Terhadap Pasien GGK yang Menjalani Hemodialisa di Unit Hemodialisa RSUP Dr. M. Djamil Padang

\begin{tabular}{l|cc}
\hline Dukungan Petugas & $\begin{array}{c}\text { Frekuensi } \\
\text { (f) }\end{array}$ & $\begin{array}{c}\text { Persentase } \\
(\mathbf{\%})\end{array}$ \\
\hline Tinggi & 39 & 60,0 \\
Rendah & 26 & 40,0 \\
\hline Total & $\mathbf{6 5}$ & $\mathbf{1 0 0}$ \\
\hline
\end{tabular}

Berdasarkan tabel 2 dapat dilihat bahwa dari 65 orang responden didapatkan lebih dari separoh $39(60,0 \%)$ yang mendapatkan dukungan petugas yang tinggi untuk menjalani hemodialisa di Unit Hemodialisa

\section{Tabel 3}

Rendam kaki air hangat adalah salah satu terapi hipertensi y

Distribusi Frekuensi Kepatuhan Pasien GGK Yang Menjalani Hemodialisa di Unit Hemodialisa RSUP Dr. M. Djamil Padang Tahun 2016

\begin{tabular}{ccc}
\hline $\begin{array}{c}\text { Kepatuhan } \\
\text { Pasien }\end{array}$ & $\begin{array}{c}\text { Frekuensi } \\
(\mathbf{f})\end{array}$ & $\begin{array}{c}\text { Persentase } \\
(\mathbf{\%})\end{array}$ \\
\hline Patuh & 23 & 35,4 \\
Tidak Patuh & 42 & 64,6 \\
\hline Total & $\mathbf{6 5}$ & $\mathbf{1 0 0}$ \\
\hline
\end{tabular}

Berdasarkan tabel 4 dapat dilihat bahwa dari 65 responden didapatkan lebih dari separoh $42(64,6 \%)$ pasien tidak patuh menjalani hemodialisa di Unit Hemodialisa RSUP Dr. M Djamil Padang Tahun 2016. 
petugas kesehatan dengan kepatuhan pasien GGK menjalani hemodialisa di Unit Hemodialisa RSUP Dr.

\section{Hasil Analisa Bivariat}

Tabel 4. Hubungan Motivasi Pasien dengan Kepatuhan Pasien GGK yang Menjalani Hemodialisa di Unit Hemodialisa RSUP Dr. M. Djamil Padang Tahun 2016

\begin{tabular}{|c|c|c|c|c|c|c|c|c|}
\hline \multirow{3}{*}{$\begin{array}{l}\mathbf{N} \\
\mathbf{0}\end{array}$} & \multirow[t]{3}{*}{ Motivasi } & \multicolumn{4}{|c|}{ Kepatuhan } & \multirow{2}{*}{\multicolumn{2}{|c|}{ Jumlah }} & \multirow{3}{*}{$\begin{array}{l}\mathbf{P} \\
\text { value }\end{array}$} \\
\hline & & \multicolumn{2}{|c|}{ Patuh } & \multicolumn{2}{|c|}{$\begin{array}{l}\text { Tidak } \\
\text { Patuh }\end{array}$} & & & \\
\hline & & $\mathbf{f}$ & $\%$ & f & $\%$ & $\mathbf{f}$ & $\%$ & \\
\hline 1. & Tinggi & 20 & 66.7 & 10 & 33.3 & 30 & $\begin{array}{c}10 \\
0\end{array}$ & 0.000 \\
\hline 2. & Rendah & 3 & 8.6 & 32 & 91.4 & 35 & $\begin{array}{c}10 \\
0\end{array}$ & \\
\hline & mlah & 23 & 45.4 & 42 & 64.6 & 65 & 100 & \\
\hline
\end{tabular}

Berdasarkan tabel 4 dapat dilihat bahwa kepatuhan pasien GGK yang tidak patuh lebih banyak didapatkan pada motivasi pasien yang rendah $32(91,4 \%)$ dibandingkan dengan motivasi pasien yang tinggi $10(33,3 \%)$. Hasil uji statistik Chi-Square didapatkan nilai $\mathrm{p}$ value sebesar 0,000 maka ada hubungan motivasi pasien dengan kepatuhan pasien GGK yang menjalani hemodialisa di Unit Hemodialisa RSUP Dr. M. Djamil Padang Tahun 2016.

Tabel 5. Hubungan Dukungan Petugas Kesehatan dengan Kepatuhan Pasien GGK yang Menjalani Hemodialisa di Unit Hemodialisa

\begin{tabular}{|c|c|c|c|c|c|c|c|c|}
\hline \multirow{3}{*}{$\begin{array}{l}\mathbf{N} \\
\mathbf{o}\end{array}$} & \multirow{3}{*}{$\begin{array}{l}\text { Dukungan } \\
\text { Petugas }\end{array}$} & \multicolumn{4}{|c|}{ Kepatuhan Pasien } & \multirow{2}{*}{\multicolumn{2}{|c|}{ Jumlah }} & \multirow{3}{*}{$\begin{array}{l}P \\
\text { value }\end{array}$} \\
\hline & & \multicolumn{2}{|c|}{ Patuh } & \multicolumn{2}{|c|}{$\begin{array}{c}\text { Tidak } \\
\text { Patuh }\end{array}$} & & & \\
\hline & & $\mathbf{F}$ & $\%$ & $\mathbf{f}$ & $\%$ & $\mathbf{f}$ & $\%$ & \\
\hline 1. & Tinggi & 22 & 56.4 & 17 & 43.6 & 39 & 100 & 0.000 \\
\hline 2. & Rendah & 1 & 3.8 & 25 & 96.2 & 26 & 100 & \\
\hline & Jumlah & 23 & 35.4 & 42 & 64.6 & 65 & 100 & \\
\hline
\end{tabular}

Berdasarkan tabel 5 dapat dilihat bahwa kepatuhan pasien yang tidak patuh lebih banyak didapatkan pada pasien yang mendapatkan dukungan petugas yang rendah $25(96,2 \%)$ dibandingkan pasien yang mendapatkan dukungan petugas yang tinggi 17 $(43,6 \%)$.

Hasil uji statistik Chi-Square didapatkan nilai $\mathrm{p}$ value sebesar 0,000 maka ada hubungan dukungan

\section{PEMBAHASAN}

Berdasarkan hasil penelitian bahwa 65 orang responden didapatkan lebih dari separoh $(53,8 \%)$ memiliki motivasi yang rendah di Unit Hemodialisa RSUP Dr. M. Djamil Padang tahun 2016. Motivasi merupakan sesuatu yang mendorong atau pendorong seseorang bertingkah laku untuk mencapai tujuan tertentu (Saam \& Wahyuni, 2012). Saam dan Wahyuni (2012) menyatakan motivasi itu bermacam-macam, dilihat dari pihak yang menggerakkan, motivasi terbagi dua yaitu motivasi intrinsik dan motivasi ekstrinsik. Motivasi intrinsik bisa didapatkan melalui adanya niat dan usaha serta keinginan yang kuat dari dalam diri seseorang, sedangkan motivasi ekstrinsik bisa diperoleh melalui lingkungan serta dukungan dari orang-orang yang ada disekitarnya. Penelitian membuktikan bahwa motivasi yang tinggi memiliki hubungan yang kuat dengan kepatuhan (Kamerrer, 2007).

Menurut asumsi peneliti bahwa pasien yang memiliki motivasi yang rendah menolak untuk melakukan hemodialisa dipengaruhi oleh motivasi intrinsik dan ekstrinsik yang kurang. Dengan frekuensi hemodialisa yang 2-3x seminggu tentu akan membuat pasien menjadi jenuh, belum lagi jarak antara tempat tinggal pasien dengan tempat hemodialisa yang jauh hal ini juga menjadi salah satu penyebab rendahnya motivasi pasien. Oleh sebab itu, motivasi dari orang-orang yang ada disekitarnya sangat berarti bagi penderita GGK yang melakukan hemodialisa khususnya dari pihak keluarga.

Salah satu bentuk rendahnya motivasi pasien terlihat dari pertanyaan yang dijawab oleh responden yaitu diantaranya : selama pasien melakukan hemodialisa pasien tidak pernah diberi semangat oleh teman sesama hemodialisa untuk rutin melakukan hemodialisa $(42.7 \%)$, pasien tidak pernah merasa kecewa jika tidak melakukan hemodialisa (46.2\%), kadang-kadang pasien merasa dengan melakukan hemodialisa hanya dapat 
menambah bebannya dan kelurganya (49.2\%), serta pasien tidak pernah melakukan hemodialisa atas kesadarannya sendiri (49.6\%).

Berdasarkan hasil penelitian dapat dilihat bahwa 65 orang responden didapatkan lebih dari separoh $(60,0 \%)$ mendapatkan dukungan petugas yang tinggi di Unit Hemodialisa RSUP Dr. M. Djamil Padang tahun 2016.

Berdasarkan hasil penelitian terdapat 39 orang responden menyatakan bahwa petugas kesehatan selalu menyarankan atau mengingatkan pasien untuk tetap melakukan hemodialisa secara rutin. Keterlibatan tenaga kesehatan sangat diperlukan oleh pasien dalam hal sebagai pemberi pelayanan kesehatan. Dukungan petugas kesehatan merupakan faktor yang dapat mempengaruhi perilaku kepatuhan (Niven, 2012). Dukungan dari petugas kesehatan memiliki peran yang sangat penting dalam menunjang kepatuhan pengobatan khususnya kepatuhan pasien GGK menjalani hemodialisis (Niven, 2012).

Menurut sebagian besar responden, petugas kesehatan lain selain dokter tidak semua memberikan informasi yang cukup berkaitan dengan penyakit yang dideritanya khususnya perawat. Perawat lebih sering mengerjakan pekerjaan teknis proses hemodialisa. Selain itu, menurut pasien bahwa perawat masih kurang memperhatikan aspek dukungan informasional kepada mereka, meskipun mereka merasa didorong oleh perawat untuk mandiri dan beradaptasi terhadap aktivitas keseharian setelah sakit pada saat awal menjalani hemodialisa.

Bentuk rendahnya dukungan petugas kesehatan dapat dilihat dari pertanyaan pasien GGK yaitu petugas kesehatan kadang-kadang memberikan pujian ketika pasien melakukan hemodialisa $(41.5 \%)$ dan petugas kesehatan kadang-kadang tidak peduli dengan rasa pusing yang pasien rasakan setelah melakukan hemodialisa $(48.1 \%)$.

Menurut asumsi peneliti dukungan petugas sangat penting untuk kepatuhan pasien disebabkan masih banyaknya pasien yang kurang mengetahui penyebab serta akibat apabila pasien tidak melakukan hemodialisa. Dukungan petugas yang sangat penting untuk pasien yaitu dukungan edukasi karena dengan adanya edukasi yang diberikan oleh petugas kesehatan baik itu yang berupa penyuluhan dapat menambah pengetahuan pasien GGK mengenai penyakitnya seperti pentingnya melakukan hemodialisa untuk menghindari komplikasi. Dengan adanya sikap dan dukungan yang baik dari petugas kesehatan, penderita GGK diharapkan mampu meningkatkan kepatuhannya untuk menjalani hemodialisa.

Berdasarkan hasil penelitian didapat bahwa 65 orang responden didapatkan lebih dari separoh (64.6\%) tidak patuh menjalani hemodialisa di Unit Hemodialisa RSUP Dr. M. Djamil Padang tahun 2016. Kepatuhan menurut World Health Organization (WHO, 2003) didefinisikan sebagai tingkatan perilaku seseorang yang mendapatkan pengobatan, mengikuti diet dan melaksanakan perubahan gaya hidup sesuai dengan rekomendasi pemberi pelayanan kesehatan.

Kepatuhan dalam hemodialisa ini sangat diperlukan untuk mempertahankan kehidupan. Apabila pasien tidak patuh dalam menjalani hemodialisa akan berdampak sangat buruk karena akan berpengaruh terhadap terjadinya komplikasi akut dan kronis. Kepatuhan terapi hemodialisa juga berdampak pada berbagai aspek perawatan pasien, termasuk konsistensi kunjungan, serta pembatasan makanan dan cairan (Syamsiah, 2011).

Apabila pasien tidak membatasi jumlah asupan cairan maka cairan akan menumpuk didalam tubuh dan akan menimbulkan edema disekitar tubuh seperti tangan, kaki, dan muka. Banyak penumpukan cairan terjadi di rongga perut yang membuat perut ascites, kondisi ini akan membuat tekanan darah meningkat dan memperberat kerja jantung. Penumpukan cairan juga masuk ke paru-paru sehingga pasien mengalami sesak nafas. Karena itulah perlunya pasien mengontrol dan membatasi jumlah asupan cairan yang masuk dalam tubuh. (Brunner \& Suddart, 2002).

Menurut Niven (2002) salah satu syarat untuk mengembangkan kepatuhan adalah mengembangkan tujuan kepatuhan. Adapun tujuan kepatuhan pada penelitian ini yaitu agar kondisi pasien tetap dapat dipertahankan dan dapat dipantau dari komplikasi yang mungkin 
terjadi seperti anemia dan hipertensi yang kemudian dapat dicegah atau dihambat dengan pemberian antihipertensi, eritropoetin, suplemen besi dan suplemen kalsium. Banyak dari pasienpasien yang tidak patuh pernah memiliki tujuan untuk mematuhi nasihat-nasihat medis pada awalnya akan tetapi setelah lama menjalani hemodialisa mengalami kebosanan dan menganggap bahwa keadaanya tidak membaik dan kurangnya dukungan keluarga.

Pada penelitian ini responden yang dianggap patuh yaitu menjalani jadwal rutin hemodialisa selama 2 kali atau lebih dari 2 kali dalam seminggu dan tidak ada keterangan tidak hadir. Adapun pada responden yang tidak patuh dapat terlihat tidak adanya anggota keluarga yang menemani ataupun keadaan badannya yang membengkak karena timbunan cairan yang tidak dapat diekskresi melalui berkemih ataupun berkeringat dan dapat berujung pada mortalitas melalui berkemih ataupun berkeringat.

Terdapat ada hubungan motivasi dengan kepatuhan pasien GGK yang menjalani Hemodialisa di RSUP Dr. M. Djamil Padang tahun 2016. Pada penelitian ini ditemukan $33,3 \%$ pada motivasi pasien yang tinggi tidak patuh dikarenakan karena kurangnya motivasi atau dukungan dari orang lain, disini terlihat bahwa responden kurang mendapatkan motivasi dari teman-teman yang sama-sama melakukan hemodiaisa selain motivasi dari dirinya sendiri, motivasi yang berasal dari orang lain (ekstrinsik) juga diperlukan oleh pasien supaya pasien labih patuh lagi dalam menjalani hemodialisa.

Kepatuhan dapat dipengaruhi oleh berbagai faktor, diantaranya keyakinan, sikap dan motivasi pasien, pengetahuan, persepsi, harapan pasien, dukungan sosial keluarga, dan dukungan petugas kesehatan (Niven, 2012 dan Kamerrer, 2007). Motivasi dan harapan merupakan salah satu faktor yang dapat meningkatkan kepatuhan pasien. Motivasi merupakan sesuatu yang mendorong atau pendorong seseorang bertingkah untuk mencapai tujuan tertentu (Saam \& Wahyuni, 2012), sedangkan harapan merupakan keinginan yang ingin dicapai oleh manusia. Motivasi dan harapan sangat diperlukan untuk membantu seseorang meningkatkan kepatuhan dalam menjalani terapi hemodialisa. Kepatuhan pasien terhadap rekomendasi dan perawatan dari pemberi pelayanan kesehatan adalah hal yang penting untuk kesuksesan suatu intervensi. Kepatuhan dalam hemodialisa ini sangat diperlukan untuk mempertahankan kehidupan. Apabila pasien tidak patuh dalam menjalani hemodialisa akan berdampak sangat buruk karena akan berpengaruh terhadap terjadinya komplikasi akut dan kronis. Kepatuhan terapi hemodialisa juga berdampak pada berbagai aspek perawatan pasien, termasuk konsistensi kunjungan, serta pembatasan makanan dan cairan (Syamsiah, 2011).

Pada penelitian ini ditemukan $(43,6 \%)$ responden yang mendapatkan dukungan petugas yang tinggi tidak patuh menjalani hemodialisa dikarenakan kurangnya dukungan yang diberikan oleh petugas. Dukungan yang diberikan oleh petugas sangat berarti bagi pasien. Menurut asumsi peneliti ada hubungan dukungan petugas kesehatan dengan kepatuhan pasien GGK menjalani hemodialisa dikarenakan dukungan dari petugas kesehatan dapat meningkatkan kepatuhan pasien dalam pengobatan. Pasien yang melakukan terapi hemodialisa memerlukan dukungan dari petugas kesehatan. Dukungan petugas kesehatan sangat penting bagi pasien yang menjalani terapi hemodialisa dan merupakan salah satu faktor yang mempengaruhi kepatuhan pasien GGK untuk menjalani hemodialisa. Dukungan mereka berguna saat pasien mengahadapi keadaan bahwa perilaku sehat merupakan hal yang sangat penting.

\section{KESIMPULAN}

Setelah dilakukan penelitian pada 65 orang responden didapatkan hubungan yang bermakna antara motivasi pasien dan dukungan petugas dengan kepatuhan pasien GGK yang menjalani Hemodialisa di RSUP Dr. M. Djamil Padang tahun 2016.. Diharapkan perawat diruangan hemodialisis agar tetap mempertahankan kinerja dan lebih aktif lagi dalam memberikan bimbingan atau penyuluhan tentang kepatuhan pasien GGK untuk menjalani hemodialisis agar pasien tetap patuh terhadap hal-hal yang disarankan oleh petugas kesehatan. 
[13] kesehatan. Jakarta: Rineka Cipta.

[14] . (2007). Promosi Kesehatan dan Ilmu Perilaku. Jakarta : Rineka Cipta.

[15] . (2012). Metodologi penelitian kesehatan. Jakarta: Rineka Cipta.

[16] Nursalam. (2011). Manajemen Keperawatan : Aplikasi dalam praktek keperawatan professional, Jakarta : Salemba Medika.

\section{DAFTAR PUSTAKA}

[1] Andre, S. (2015). Hubungan dukungan keluarga dengan kepatuhan hemodialisa pada pasien gagal ginjal kronik di ruangan unit hemodialisa RSUP Dr. M. Djamil Padang. Skripsi : Tidak dipublikasikan.

[2] Carpenito, L. J. (2000). Buku saku diagnosa keperawatan. Jakarta: EGC.

[3] Dani, Rahma. (2015). Hubungan motivasi, harapan, dan dukungan petugas kesehatan terhadap kepatuhan pasien gagal ginjal kronik menjalani hemodialisis. Skripsi : Tidak dipublikasikan.

[4] Friedman, M.M., Bowden, V.R., \& Jones, E.G. (2003). Family nursing, research, theory, and practice. New Jersey: Prentice Hall.

[5] Format referensi elektronik direkomendasikan oleh Lubis, A. J. (2006). Dukungan sosial pada pasien gagal ginjal terminal. Skripsi diperoleh dari http://library.usu.ac.id, diperoleh 13 Desember, 2015

[6] Hamid, A. (2010). Faktor-faktor yang mempengaruhi pasien gagal ginjal kronik menolak untuk melakukan hemodialisis. Skripsi PSIK UR: Tidak dipublikasikan.

[7] Hastono, S. P. (2007). Analisa data kesehatan. Jakarta: Fakultas Kesehatan Masyarakat Universitas Indonesia.

[8] Hidayat, A. A. (2007). Metode penelitian keperawatan dan teknik analisis data. Jakarta: Salemba Medika.

[9] Kammerer, J., Garry, G., Hartigan, M., Carter, B., Erlich, L. (2007). Adherence inpatient on dialysis: Strategi for success. Nephrology Nursing Journal, 34(5), 479-486.

[10] Muttaqin, A., \& Sari, K. (2011). Asuhan keperawatan gangguan sistem perkemihan. Jakarta: Salemba Medika.

[11] Niven, N. (2012). Psikologi kesehatan: Pengantar untuk perawat \& profesional kesehatan lain. Jakarta: EGC.

[12] Notoatmodjo, S. (2005). Metodologi penelitian kesehatan. Jakarta: Rineka Cipta.
[17] Nursalam. (2013). Konsep dan penerapan metodologi penelitian ilmu keperawatan. Jakarta: Salemba Medika. . (2006). Asuhan keperawatan pada pasien dengan gangguan sistem perkemihan. Jakarta: Medika Salemba.

[19] Pencatatan dan Pelaporan Tahunan Ruangan Hemodialisa RSUP Dr. M. Djamil Padang. (2015). Jumlah penderita gagal ginjal kronik. Padang : RSUP Dr. M. Djamil. Tidak dipublikasikan.

[20] Padila. (2012). Keperawatan medikal bedah. Yogyakarta : Nuha medika

[21] Rini, S. (2013). Hubungan dukungan keluarga terhadap kepatuhan dalam pembatsan asupan nutrisi dan cairan pada pasien gagl ginjal kronik dengan hemodialisa. Skripsi PSIK UR. Tidak dipublikasikan.

[22] Riskesdas. 2013. Riset Kesehatan Dasar. Badan Penelitian Dan Kesehatan. Diakses tanggal 15 Februari 2016.

[23] Saam, Z., \& Wahyuni, S. (2012). Psikologi keperawatan. Jakarta: PT Raja Grafindo Persada.

[24] Smeltzer, S., \& Bare, B. (2002). Buku ajar keperawatan medikal bedah Brunner \& Suddarth. Jakarta: EGC.

[25] Sunaryo. (2004). Psikologi untuk keperawatan. Jakarta: EGC.

[26] Syamsiah, N. (2011). Faktor-faktor yang berhubungan dengan kepatuhan pasien CKD yang menjalani hemodialida di RSPAU Dr Esnawan Antariksa Halim Perdana Kusuma Jakarta.

[27] Wijaya, A.S \& Putri, Y.M. (2013). Keperawatan medikal bedah. Yogyakarta : Nuha medika. 